\title{
O Método Cartográfico no projeto da Arquitetura da Paisagem
}

\author{
Luciana Bongiovanni Martins Schenk, \\ Maria Cecília Pedro Bom de Lima*
}

Resumo O artigo apresenta uma reflexão teórica acerca do Método Cartográfico como estratégia para o processo de leitura da cidade e projeto em Arquitetura da Paisagem. Discorre sobre a relação histórica entre Cartografia e Paisagem, explicitando articulações entre Ciência e Arte e partindo da ideia de Cartografia como representação do mundo até sua concepção como estratégia metodológica. A descrição desse percurso busca criticar métodos de desenvolvimento de projeto estritamente pragmáticos que definem suas ações segundo uma visão de sobrevoo, pouco relacionada às especificidades do lugar. Procura-se descrever como a Cartografia, enquanto processo, apresenta o potencial de abarcar as complexidades e polissemias da ideia de Paisagem.

Palavras-chave: paisagem, cartografia, projeto.

\section{The Cartographic Method in Landscape Architecture design}

\begin{abstract}
The paper presents a theoretical reflection on the Cartographic Method as a strategy for the interpretation of landscape and landscape design. It discusses the historical relationship between Cartography and Landscape indicating articulations between Science and Art and starting from the idea of Cartography as a representation of the world up to its conception as a methodological strategy. The description of this path seeks to criticize design methods that are strictly pragmatic and define actions according to an overfly vision unrelated to the specificities of the place. The paper describes how Cartography as a process presents the potential to encompass the complexities and polysemy of Landscape.
\end{abstract}

Keywords: landscape, cartography, landscape design.

\section{El Método Cartográfico en el diseño del paisaje}

Resumen El artículo presenta una reflexión teórica acerca del Método Cartográfico como estrategia para el proceso de lectura de la ciudad y proyecto del Paisaje. Discurre sobre la relación histórica entre Cartografía y Paisaje, explicitando articulaciones entre Ciencia y Arte y partiendo de la idea de Cartografía como representación del mundo hasta su concepción como estrategia metodológica. La descripción de este camino busca criticar métodos de desarrollo de proyecto estrictamente pragmáticos que definen sus acciones según una visión de sobrevuelo, poco relacionada a las especificidades del lugar. Se busca describir cómo la Cartografía, en cuanto proceso, presenta el potencial de abarcar las complejidades y polisemias de la idea de Paisaje.

Palabras clave: paisaje, cartografía, proyecto. 
* Luciana Bongiovanni Martins Schenk é Arquiteta e Urbanista, professora do Instituto de Arquitetura e Urbanismo da Universidade de São Paulo, ORCID <https://orcid.org/0000-00027944-7782>. Maria Cecília Pedro Bom de Lima é Arquiteta e Urbanista, mestranda no Programa de Pós Graduação em Arquitetura e Urbanismo do Instituto de Arquitetura e Urbanismo da Universidade de São Paulo, ORCID $<$ https://orcid.org/0000-00020142-1830>

10 presente trabalho foi realizado com apoio da Coordenação de Aperfeiçoamento de Pessoal de Nível Superior - Brasil (CAPES).
C ste artigo é desenvolvido através do entrelaçamento de dois temas principais: a Paisagem e a Cartografia ${ }^{1}$. Foram identificados potenciais contatos entre o histórico de discussão desses campos de conhecimento que podem evidenciar questões relevantes para se pensar o projeto de espaços livres no contexto da cidade contemporânea.

O tema da Paisagem inserido na realidade urbana atual é acompanhado por um debate ambientalista fortemente difundido a partir da segunda metade do século XX. Autores como lan McHarg (1969), Anne Spirn (1995) e Michael Hough (1998) impulsionaram a proposição de alternativas de planejamento e construção de regiões e cidades, tendo em vista o potencial diálogo entre processos urbanos, em especial de crescimento, e processos naturais.

A relação entre esses processos enquanto objeto de investigação e projeto já estava presente em intervenções na paisagem no século XIX, como o Sistema de Parques elaborado por Frederick Law Olmsted, chamado Emerald Necklace, em Boston (1870); esse projeto articulou de modo pioneiro questões de infraestrutura e sociabilidade. Planejando esses espaços Olmsted buscava, segundo o testemunho de seus escritos, elaborar acerca da presença da Natureza na cidade enquanto congruência, evitando os já visíveis conflitos causados pelo processo de desenvolvimento industrial e crescimento urbano. Ao lado de seu sócio, o arquiteto Calvert Vaux, construiu em novo registro essa presença: a circulação das águas e sua drenagem, o modelado do relevo e a constituição da vegetação e seu papel na cidade foram equacionados a partir daquilo que se denominava à época princípio orgânico. Tal princípio não se restringia apenas ao trato das questões físicas em uma dimensão mais naturalizada, mas pretendia aproximar o cidadão da experiência da Natureza, algo que operava como um bálsamo em relação à dura contraparte impingida pela vida nas cidades. Essa ação de planejamento e projeto, que conspirava na construção de um especial olhar, transformando Natureza em Paisagem, promovia lugares de encontro e lazer, guardando importante dimensão cultural e social nos espaços livres urbanos (SCHENK, 2008).

Dentro de uma contemporânea realidade cultural e urbana, a questão que se apresenta é: quais são as paisagens possíveis? E a pergunta se desdobra: como empreender seu projeto?

A relação entre processos naturais e processos urbanos mostrou-se fundamental na retomada do tema no contexto de finais do Século $X X$, que potencializou a crítica às soluções de cunho eminentemente técnico e ampliou a discussão acerca da busca pelo equilíbrio entre o desenvolvimento das cidades e os aspectos físicos e ecológicos do ambiente.

Considerando a gradativa difusão do discurso ambientalista, principalmente a partir da década de 1980, falar em projeto da paisagem nos dias de hoje, geralmente supõe abordar 
2 No prefácio, Silvestri e Aliata alinhando-se à tese de Gombrich (1972) afirmam: para que exista Paisagem, não basta que exista Natureza, é necessário um ponto de vista do espectador guiado pela arte. A separação de Sujeito e Objeto, Homem e Mundo, entrevê na Paisagem um meio de pensar a relação artifício/natureza, temas a princípio compreendidos separadamente, senão como oposição. Os autores firmam a ideia de que a recuperação da Antiguidade e seus valores como a unidade entre Homem e Natureza, é pressuposto programático para o Humanismo que funda o ciclo Moderno.

\footnotetext{
3 As cinco portas tratadas no ensaio são as seguintes: da paisagem como representação cultural e social, construção subjetiva que cria uma interface mental, um véu, entre homem e mundo; da paisagem como território fabricado e habitado, materialidade, sucessão de rastros, obra coletiva da sociedade; da paisagem como meio ambiente material e vivo das sociedades humanas, superação do dualismo moderno homem e natureza; da paisagem como experiência fenomenológica, exterioridade que afeta os corpos de modo pré-reflexivo; da paisagem como projeto, invenção, objeto de interesse do arquiteto paisagista (BESSE, 2014).
}

a temática da sustentabilidadee resiliência, que são conceitos vinculados principalmente ao viés ecológico e participam do campo de conhecimento da chamada Infraestrutura Verde. Esse campo, que contempla teoria e práticas, se aplica principalmente ao projeto de espaços livres de edificações, associados à mobilidade e drenagem de águas, que são estratégicos para se pensar técnicas alternativas de construção do espaço urbano que não tenham mais como modelo a chamada infraestrutura cinza, relacionada às obras de engenharia em geral (HERZOG; ROSA, 2010).

A despeito de sua positiva contribuição na busca por valores que possam engendrar uma relação mais equilibrada entre Natureza e Cidade, a predominância da chave ecológica no tratamento dos projetos de espaços livres de edificação parece deixar de lado outros aspectos essenciais à ideia de Paisagem. Tais aspectos se referem à realidade vivida, sociocultural, de memória e patrimônio, ao espaço percebido e suas dimensões, que muitas vezes não são contempladas, ou são pouco exploradas no processo de projeto desses espaços.

Neste artigo, propomos evidenciar a complexidade no tratamento das questões relacionadas ao projeto de Paisagem. A abordagem ecológica é um dos vetores que participa do estudo, mas não o esgota, sendo vital a articulação dessa matriz às valências estéticas que alicerçam a vida e potencialmente explicitam o contato entre Homem e Natureza, construindo assim, a Paisagem (ALIATA; SILVESTRI, 2008)².

Um importante fio condutor acerca dessas valências tem suas origens nas abordagens culturais da paisagem (ROGER, 2007; BERQUE, 1994). Esses autores investigam as muitas camadas que esse espaço das práticas do cotidiano guarda, referentes à vivência, à memória e à cultura, ao jogo e à experiência, isto é, ao palco dos acontecimentos e da vida na cidade.

Segundo Alain Roger (2007), existe uma relação fundamental entre meio ambiente (objeto científico) e paisagem (objeto estético), sendo que um não se reduz ao outro. A abordagem aqui proposta conspira por esse contato, dando ênfase para a discussão sobre a dimensão estética da paisagem (ALIATA; SILVESTRI, 2008).

A possibilidade de traduzir esse percurso, a investigação de espaços e lugares, e as múltiplas camadas que concorrem na produção de uma paisagem, em estratégia metodológica de projeto é o que move o artigo. São discutidas possibilidades de ação no campo da arquitetura da paisagem, tendo em vista encaminhamentos e escolhas que não se pautam em questões estritamente pragmáticas e técnicas, mas que abarcam, em seu processo de formulação, dimensões expressivas e poéticas da paisagem, diante de sua realização enquanto experiência.

A paisagem é termo polissêmico apropriado por diversos campos do conhecimento, que guarda a perspectiva de possuir diferentes definições a partir desses campos. Jean-Marc Besse, autor do livro "O gosto do Mundo: exercícios de paisagem" (2014), discorrendo acerca dessa multiplicidade, propõe a coexistência dessas definições e suas valências não como um problema que fragiliza sua operação, mas como potência que amplia sua significação. No capítulo, "As cinco portas da paisagem", o autor apresenta a coexistência de diferentes pontos de vista, que não ambicionam a definitiva verdade acerca do termo, mas colecionam perfis próprios de seus campos de conhecimento ${ }^{3}$. 
A noção de paisagem, sendo polissêmica e passível de múltiplas interpretações por distintos campos disciplinares, recusa respostas unívocas diante de sua constituição complexa. Da mesma forma sugerimos a pertinência do Método Cartográfico (PASSOS, KASTRUP e ESCÓSSIA, 2015), que tem matriz no pensamento rizomático de Deleuze e Guattari (1980) como possibilidade de investigação capaz de operar tal complexidade sem reduzi-la e esvazia-la (KASTRUP, 2015) e, ao relacionar complexidades, apresentarse como proposição potencialmente capaz de promover um percurso contemporâneo de projeto da paisagem.

Por reunir as dimensões objetiva e subjetiva, o Método Cartográfico possibilitaria a promoção de uma estratégia de apreensão das qualidades da paisagem de um lugar, no sentido de, ao agenciar suas representações, possibilitando a relação entre elas, promover a articulação entre o espaço real e suas potencialidades, entre o mundo objetivo e subjetivo.

No que tange à complexidade, a estratégia metodológica constitui uma base relevante para o desenvolvimento de projetos de espaços livres especialmente porque contempla o processo criativo em sua dimensão transversal permitindo o estabelecimento de relações entre chaves que normalmente não estariam implicadas: a investigação, representação e mobilização de informações, a leitura das diversas camadas que compõem o espaço, propiciam a descoberta e explicitação de potencialidades, revelando qualidades desse espaço que podem contribuir, diversificar e complexificar a leitura e o projeto da paisagem.

40 esforço descritivo (de inventário) dos cartógrafos era complementado pela representação pictórica que dava ênfase ao fenômeno e a uma visão menos pragmática do mundo, o que contribuiu na formação da ideia multifacetada e complexa de Paisagem ao longo dos séculos seguintes: "Alexander von Humboldt, cuja obra mestra Cosmos, (1845), Ihe confere forte participação na fundação da Geografia como campo de conhecimento, concede à pintura um status privilegiado como meio de contemplação da fisionomia da natureza. Embora o naturalista prussiano defendesse o mérito da experiência sobre a representação, percebia na arte de pintar paisagens e apresentá-las ao observador remoto, um meio de fazê-lo participar desse momento único de comunhão e totalidade, (...)" (SCHENK, 2008, p. 15).

\section{Cartografia e Paisagem: diálogo e ruptura entre ciência e arte}

Em breve percurso acerca da Cartografia e suas representações, procuramos identificar questões que a qualificam enquanto método em seus desdobramentos contemporâneos. Coetaneamente, percorremos o desenvolvimento da ideia de Paisagem relacionada à abordagem cartográfica, estabelecendo assim o contato histórico entre Cartografia e Paisagem.

A cartografia como ferramenta científica foi desenvolvida como modo de representar o território principalmente a partir da elaboração do sistema de coordenadas pautado na descrição matemática da superfície da Terra segundo Ptolomeu (Século I d.C.). Sua redescoberta no Século XV foi um dos motivos constitutivos do ponto de inflexão entre a cartografia medieval, impregnada de discursos religiosos e mitológicos, e a cartografia do início do período Moderno (SCAFI, 1999).

Observando o contexto ocidental europeu, os temas da cartografia e da paisagem se relacionaram desde o Renascimento e o surgimento da pintura que tem como temática a paisagem. Javier Maderuelo (2008) destaca a imbricação entre ciências e artes a partir do Renascimento, confirmando o vínculo entre cartografia e a pintura, que tinha por objeto a Paisagem ${ }^{4}$.

Nesse contexto, a imbricação entre Cartografia e Pintura é explicitada por um objetivo comum entre essas duas práticas: apreender e representar o mundo. Em consonância com Maderuelo, Jean-Marc Besse afirma essa primeira perspectiva em que Ciência e Arte (Cartografia e Pintura) não se configuram em territórios apartados e que, 
... o pintor e o cartógrafo, ambos observadores de espaços e de fenômenos do mundo terrestre, desenvolvem uma arte da leitura visual dos signos que constituem a qualidade própria de uma paisagem (BESSE, 2006, p. 19).

Nas cartografias renascentistas, a observação do mundo era orientada por um esforço de apreensão total do território, ponto de vista pouco acessível na época, a não ser a partir de um ponto elevado: um morro, uma torre. A visão superior representada nessas cartografias refletia uma mentalidade, um desejo dos homens em acessar uma paisagem, em abarcar todo o território através da visão, prática impossibilitada por limitações técnicas (BESSE, 2014).

Essa representação, que dependia fortemente da imaginação, participa de um período no qual Ciência e Arte ainda estavam alinhadas. O que se representava era fruto do esforço criativo que construía o conhecimento do território habitado.

Besse (2014) desenvolve essa abordagem crítica sobre a relação entre Cartografia e Paisagem tendo como foco a passagem que vai de um contato em complementariedade, construído ao longo de três Séculos a partir do Renascimento, até a ruptura provocada pela Cartografia Científica. O contato num primeiro tempo, e a ruptura num segundo momento, são a explicitação dos modos de ver o mundo desses períodos, que manifestam distintas maneiras de apreender e representar esse mundo.

As transformações tecnológicas que permitiram outros pontos de vista do território alteraram o objeto cartográfico em seu conteúdo e qualidade. O advento de técnicas que promoveram a observação e registro da superfície terrestre vista de cima proporcionou a concretização de um desejo presente desde as pinturas de paisagem renascentistas, e que se manteve no plano utópico até o Século XIX (BESSE, 2014).

O mapa adquiriu cada vez mais precisão na medida em que a representação da superfície terrestre vista de cima não dependia apenas da imaginação, mas se apoiava em técnicas de registro de um olhar efetivo, crescentemente informado pela Ciência de matriz positivista.

O desenvolvimento técnico da capacidade de voar gera uma condição de afastamento jamais experienciada, contribuindo na criação das condições de uma representação unívoca, científica e portadora de rígido código que é capaz de ser lido e interpretado por diferentes sujeitos em diferentes culturas: a Cartografia Científica.

Desenvolve-se posteriormente um discurso que critica esse novo olhar sobre o mundo e seu distanciamento das coisas; o afastamento físico guarda implicações metafísicas. O território abarcado pelo olhar de sobrevoo não diria mais respeito à participação do observador em processos que constroem o mundo vivido, mas, ao contrário, referir-se-ia a uma superfície transformada principalmente pela ação do homem segundo um ponto de vista generalista e pouco ligado às particularidades do território em observação. Essa ação apresentava um bônus e um ônus: o bônus do esforço generalizador, vital a uma ciência ocupada em explicar o mundo; o ônus da perda das especificidades daquele lugar em particular.

Como forma de questionar a orientação positivista da ciência desse período, uma ciência que "manipula as coisas e renuncia habitá-las" (MERLEAU-PONTY, 2013, 
5 A respeito da deterioração dos procedimentos que organizam as cidades e das próprias cidades, Certeau afirma: "Ao invés de permanecer no terreno de um discurso que mantém o seu privilégio invertendo o seu conteúdo (que fala de catástrofe e não mais de progresso), pode-se enveredar por outro caminho: analisar as práticas microbianas, singulares e plurais, que um sistema urbanístico deveria administrar ou suprimir e que sobrevivem a seu perecimento; seguir o pulular desses procedimentos que, muito longe de ser controlados ou eliminados pela administração panóptica, se reformaram em uma proliferação ilegitimada, desenvolvidos e insinuados nas redes de vigilância, combinados segundo táticas ilegíveis mas estáveis a tal ponto que constituem regulações cotidianas e criatividades sub-reptícias que se ocultam somente graças aos dispositivos e aos discursos, hoje atravancados, da organização observadora" (CERTEAU, 2007, p. $174-175)$. p. 15), a filosofia se encarrega de pensar sobre os modos de apreensão do mundo. Segundo Maurice Merleau-Ponty, tal filosofia que visa, sobretudo, uma descrição das coisas, "repõe as essências na existência" (MERLEAU-PONTY, 1994, p. 1).

Retornar às coisas mesmas é retornar a esse mundo anterior ao conhecimento do qual o conhecimento sempre fala, e em relação ao qual toda determinação científica é abstrata, significativa e dependente, como a geografia em relação à paisagem - primeiramente nós aprendemos o que é uma floresta, um prado ou um riacho (MERLEAU-PONTY, 1994, p. 4).

A ideia de paisagem estabelece contato com as abordagens da fenomenologia desse período que se ampliam em relação a outros campos do conhecimento, no que diz respeito aos modos de apreender o mundo. A paisagem corresponderia a um momento pré-reflexivo (BESSE, 2014), aquilo que nos cerca e com o qual podemos estabelecer contato, para alguns autores, experiência direta, representativa do contato ingênuo (MERLEAU-PONTY, 1945) do homem com o mundo.

Na geografia, Eric Dardel (1952) apresenta a paisagem como poderoso meio pelo qual a experiência direta pode cumular de significado a análise fria de dados científicos, é antes "um conjunto, uma convergência, um momento vivido" (DARDEL, 2011, p. 31). Assim, a paisagem, longe de ser redução, círculo fechado que abarca a visão, é um desdobramento: "Ela não é verdadeiramente geográfica a não ser pelo fundo, real ou imaginário, que o espaço abre além do olhar" (DARDEL, 2011, p. 32).

Desse modo, seria possível identificar, ao longo do século XX, em especial a partir de sua segunda metade, o desenvolvimento de ideias que intentam abarcar filosoficamente a realidade sensível do mundo, resistindo a uma cientificidade que o esvazia de significados metafísicos. Essa resistência toma forma através de um esforço pelo contato direto com o real, que procura evitar o descolamento do fenômeno.

Michel de Certeau (1980), um dos autores contemporâneos que dão continuidade à crítica da visão de sobrevoo que marca a ciência positivista, é assertivo quanto à qualidade e intencionalidade dessa abordagem generalizadora, a qual, segundo o autor, é dotada de propósitos de dominação.

Aquilo que o autor denomina práticas microbianas ${ }^{5}$, que se desenvolvem embaixo, em contraponto à visão generalista, é o cerne da vida e o fundamento da compreensão dos lugares. No que diz respeito à cidade, Certeau critica a lógica de organização do espaço pautada pela visão totalizadora; em outras palavras: a lógica do planejamento do território realizada através do uso das cartografias em crescente descolamento com o real, ignoraria as complexidades características do cotidiano. O mapa produzido nesse contexto isolaria características e conspiraria contra o real, significando sua elaboração, bem como as interpretações e ações advindas dessa representação, um equívoco contra a vida.

O discurso de Certeau e a abordagem fenomenológica da paisagem vão de encontro a um campo de discussão no urbanismo relacionado às transformações da sociedade ao longo das épocas, sobretudo diante do desafio do crescimento e seu planejamento em relação à complexificação do fenômeno urbano. 
6 A expressão hodologia foi cunhada entre 1920 e 1930 por um psicólogo alemão, Kurt Lewin, estudioso do comportamento humano em relação ao meio, a partir da palavra grega hodos, caminho. Derk de Jonge a utilizará em 1967 em um artigo da revista Landscape e John Brinckerhoff Jackson reapresentará a "hodologia", primeiro em 1984, (A la découverte du paysage vernaculaire), e depois em 1994, como ciência dos caminhos, ( $A$ Sense of Place, a Sense of Time). Cf BESSE, 2014, pp. $184-189$.
Sobre a revisão contemporânea da Cartografia enquanto representação, outro geógrafo, Denis Cosgrove (1999) assevera acerca da necessidade de abarcar as transformações técnicas, políticas, econômicas e culturais que promovem novas concepções de um mundo globalizado. Pode ser identificada uma mudança de registro das representações do território da cidade, a qual passa a envolver a observação de outros espaços e outras relações entre Homem e Mundo, mais especificamente territórios que pareciam não fazer parte das dinâmicas da cidade. O que se alterou de modo fundamental foi também a percepção do que venha ser totalidade: a visibilidade e participação de espacialidades que antes se localizavam à margem do instituído, ou legalmente recortado, bem como o modo de representá-los.

\section{Cartografia e paisagem: novas articulações entre ciência e arte}

Essa alteração de percepção em registro contemporâneo permite outra aproximação entre Arte e Ciência, um nexo que se mostra relevante para compreender como Cartografia e Paisagem podem estar imbricadas diante do esforço de apreender o mundo. É justamente quando a complexidade contemporânea se apresenta, quando a crítica elaborada às perspectivas que estreitaram os significados do real se estabelece, que a Ciência parece se voltar uma vez mais aos campos artísticos, que por sua vez se colocam em novos lugares, deslizando por chaves de investigação e recepção.

Ao percorrer brevemente o fazer artístico do século XX, podem ser identificadas questões que envolveram a exploração dos modos de representação do mundo, de descoberta e descrição de fenômenos e construção de paisagens. Uma vez mais, mas em distinto registro do Renascimento, articulam-se Ciência e Arte, e por sua vez, Cartografia e Paisagem.

Nesse sentido, é possível colocar em evidência movimentos efetuados no território da cidade, entre metade do Século XIX e início do Século XX, que partem, sobretudo, de um modo de percorrer e apreender a cidade, inicialmente a partir da figura do flâneur de Baudelaire; depois através das deambulações das vanguardas modernas dos anos 1910 a 1930, que faziam parte das práticas dadaístas e surrealistas; e, finalmente, as derivas situacionistas nos anos 1950 a 1960 (JACQUES, 2005).

O caminhar e o percurso se tornam temas e práticas norteadoras para essas proposições que buscam conhecer a cidade a partir de sua experiência, promovendo as particularidades de registros, em contraposição às ações que homogeneízam o espaço urbano.

Articulando a ideia de paisagem como construção cultural, fruto de experiência fenomenológica, e os enfrentamentos, pelo campo artístico, acerca da realidade complexa da cidade contemporânea, a cartografia se coloca sob um novo registro, relacionado à ideia central de corpo em movimento que experencia a cidade para apreendê-la.

Uma abordagem possível da cartografia contemporânea é apresentada na reflexão de Besse sobre a chamada "cartografia hodológica". No ensaio "Paisagem, hodologia, psicogeografia" ${ }^{6}$, Besse distingue duas geografias: a primeira erudita, objetiva, que promove o distanciamento entre geógrafo e mundo; a segunda implica na participação do geógrafo no mundo, e se refere ao mundo vivido, - não apenas material, mas 


\footnotetext{
7 A cidade espetacularizada corresponde ao cenário urbano contemporâneo, caracterizado por "uma diminuição da participação popular, mas também da própria experiência física urbana enquanto prática cotidiana, estética ou artística" (JACQUES, 2005, p. 16)
}

também psicológico - e que, no entanto, não é pura subjetividade. A hodologia participa dessa segunda geografia e se refere à paisagem vivenciada pelos caminhos, pelos percursos.

Apresenta-se através da "cartografia hodológica" uma ideia aparentemente conflitante, se considerarmos as abordagens que indicam o mapa como objeto e prática de controle, conforme o discurso de Certeau. No entanto, trazendo as contribuições de Deleuze para este debate, Besse indica uma transformação da noção de cartografia, a qual passa a ser entendida menos como objeto de representação stricto sensu, e mais como processo de conhecimento e construção da realidade.

Ao aproximar essa concepção de cartografia ao campo da arquitetura e urbanismo, surge um paradoxo. Entendida como uma estratégia capaz de abarcar as múltiplas camadas do cotidiano da cidade, a cartografia identificada na prática do caminhar explicita essa realidade, mas encontra seus limites ao deparar-se com objetivos projetuais. Conforme observa Paola Berenstein Jacques ${ }^{7}$ (2005) acerca da crítica à chamada cidade espetacularizada, as errâncias urbanas seriam um "antídoto" contra o espaço homogêneo, uma ação de resistência contra os processos hegemônicos de explicação e compreensão da cidade. Assim, a autora constata a impossibilidade de planejar e predeterminar o espaço urbano, que é reconhecido como palco dos modos de apropriação e de participação popular capazes de subverter a homogeneidade da cidade espetacularizada.

A maior questão das intervenções não estaria na requalificação em si do espaço físico, material - pura construção de cenários - mas sim no tipo de uso que se faz do espaço público, ou seja, na própria apropriação pública desses espaços (JACQUES, 2005, p. 19).

Para o campo da arquitetura e urbanismo, tal questão se mostra particularmente inquietante, pois esvazia suas pretensões, visto que identifica no projeto uma prática que fixa processos e suprime a vitalidade e diversidade do espaço urbano.

Ao atentarmos para a chave da cartografia nessa nova perspectiva, seria possível identificar um método de aproximação que poderia agenciar diferentes representações e informações na produção de conhecimento que não se pretende único e absoluto, mas parte desse processo em contínua produção. Essa ação teria como horizonte entrelaçar experiência vivida, um possível horizonte de projeto e intervenção na cidade.

Nesse sentido, mostra-se relevante a relação entre arte e cartografia presente no trabalho de artistas da Land Art, os quais, como destaca Besse (2014):

Chegaram à cartografia a partir de um questionamento próprio da arte, relativo às relações que a obra mantém com o real, com o espaço, o tempo, a matéria e, mais geralmente, relativo aos quadros perceptivos e simbólicos da experiência do mundo (BESSE, 2014, p. 141).

A cartografia gerada a partir de questionamentos provenientes do campo da arte contemporânea é destituída de um caráter estritamente funcional e utilitarista. Mais do que instrumento operativo de propósitos políticos e econômicos, essas cartografias são 
meio, estratégia, para acessar, expor, comentar, apresenta as múltiplas camadas que compõem a paisagem e, nesse movimento, potencialmente revelam a complexidade da vida contemporânea em suas relações.

Sobre os artistas da Land Art, Besse observa ainda o seguinte:

Revelando, por e em suas obras, as dimensões reflexivas e criativas do mapa, também expuseram como este, mais que uma simples intenção de representação, carregava também em si um projeto de interpretação e transformação do território (BESSE, 2014, p. 142).

Ao contrário da produção cartográfica medieval e renascentista, o universo desses movimentos artísticos não está em imaginárias regiões desconhecidas pelos homens, ou inacessíveis pelas limitações técnicas de visualização do território; está, na verdade, inscrito na experiência, no espaço urbano vivenciado, não apenas naqueles objetos de plano e projeto, mas também no que foge à regra, em suas paisagens de margem, efêmeras, indeterminadas. O esforço criativo da nova ação cartográfica está na busca pela explicitação de lugares invisíveis à lógica dominante do espaço urbano, e que se tornam concretamente acessíveis a partir de apreensões alternativas da cidade e sociedade. A cartografia agencia o imaginário em outros registros pretendendo construir a visibilidade do real.

Essas cartografias reinventadas que se tornaram ferramentas do fazer artístico (BESSE, 2014) são o ponto de partida para se pensar a articulação entre paisagem, cartografia e ação projetual na cidade contemporânea.

Entre a cartografia objetiva (descritiva, quantitativa) e a cartografia subjetiva (de significados, intensidades, de processos, apresentação de uma realidade em seus diversos perfis) existe uma fresta, aquilo que permite o trânsito entre esses dois universos e que se apresenta como elemento promissor para essa investigação.

\section{O método cartográfico e o projeto da paisagem}

8 Os filósofos Gilles Deleuze (1925 - 1995) e Félix Guattari (1930 - 1992) redigiram a obra Mille plateaux - capitalisme et schizophrénie, originalmente publicada como volume único em 1980 A edição brasileira foi dividida em 5 volumes, publicados em 1995 pela Editora 34.

9 [Filosofia] Processo de mudanças efetivas pelas quais todo ser passa; movimento permanente que atua como regra, sendo capaz de criar, transformar e modificar tudo o que existe; essa própria mudança. ABBAGNANO, Nicola. Dicionário De Filosofia. São Paulo: Mestre Jou, 1962 p. 250.
O desenvolvimento de um Método Cartográfico, referente às novas cartografias que buscam abarcar a complexidade da realidade contemporânea, conta com autores que partem de conceitos desenvolvidos por Gilles Deleuze e Félix Guattari, sendo uma das principais referências a obra Mil Platôs $(1980)^{8}$. Nela, a cartografia é apresentada não como estrita representação de um território, que envolve objetivos de controle, dominação ou organização, mas antes como um modo de observar as multiplicidades que constroem a realidade contemporânea.

Deleuze e Guattari apresentam uma série de questões a partir das quais propõem a caracterização dos processos que promovem o devir ${ }^{9}$ da sociedade contemporânea, destacando, sobretudo, a dimensão de produção dessas dinâmicas, considerando o sentido criativo do termo.

Uma das principais questões que orienta a abordagem dos autores é a de rizoma, que se refere à multiplicidade e simultaneidade de processos que movem a vida, que não estão organizados em uma estrutura linear e não possuem um início ou um fim. 
A imagem de múltiplos platôs que se cruzam e se conectam apresentando a realidade complexa que resiste a explicações unívocas é chave que apoia o desdobramento de diversas questões que constroem o Método Cartográfico.

Tendo em vista a investigação elaborada por autores acerca das pistas do método cartográfico (PASSOS, KASTRUP e ESCÓSSIA, 2015), tentamos indicar como essa abordagem poderia ser transposta para o campo da arquitetura da paisagem enquanto estratégia, sobretudo no que diz respeito ao desenvolvimento projetual.

Esse método vem sendo utilizado em pesquisas sobre a realidade urbana contemporânea, sua complexidade e possibilidades de subversão (JACQUES; BRITTO; DRUMMOND, 2015). O que se procura ensaiar nesse artigo são desdobramentos desse processo de investigação que apresenta alternativas de intervenção nessa realidade complexa, a partir das atribuições do arquiteto da paisagem.

A cidade contemporânea apresenta uma realidade de esgarçamento em relação aos espaços tradicionais relacionados à Arquitetura da Paisagem: ruas, praças e parques são tensionados em seus registros históricos e a apreensão dos espaços livres de edificação escapa dessas tipologias e parece demandar o ensaio de novas posturas de investigação, recorte e agenciamento de informações. Isso significa a recusa de abordagens estritamente pragmáticas e técnicas, que definem "de cima" as intervenções no espaço, desconsiderando suas especificidades e imprevisibilidades.

A relação entre arte e ciência, que ocupa lugar essencial na reflexão sobre o projeto da paisagem, tendo em vista a articulação histórico-cultural entre eles, sempre aportou informações de diferentes naturezas em seus desenvolvimentos, correndo o risco atual de ter essa complexidade esvaziada pela ênfase ambiental. O Método Cartográfico convoca representações múltiplas e particulares, que diriam respeito à relação entre homem e mundo enquanto experiência, criando espaço para suas potenciais articulações, tornadas visíveis em sua complexidade.

O modo de investigação proposto pelo Método Cartográfico caracteriza o que Passos, Kastrup e Escóssia (2015) chamam de pesquisa qualitativa. Essa pesquisa se distancia da ideia de pesquisa quantitativa, convencionalmente considerada como dotada de cientificidade aferida por seus dados numéricos. Assim, uma das principais contribuições do método cartográfico para o campo da pesquisa sobre o espaço urbano seria expandir os procedimentos para abordagens processuais, apresentando as dinâmicas que caracterizam a cidade.

Uma questão fundamental do Método Cartográfico diz respeito à reversão metodológica (ALVAREZ; PASSOS, 2015), a partir da qual a pesquisa não se organiza segundo uma meta que molda a sequência de processos, mas, sim, o desenvolvimento dos processos é que define as metas. Isso demostra o caráter experimental do método em questão e a impossibilidade de uma conclusão final de pesquisa. O que existe é uma investigação permanente que se move por um "saber com" e não por um "saber sobre", e essa perspectiva ancorada no fenômeno é vital, ela envolve a implicação do pesquisador em um território existencial. Nesse sentido, o pesquisador não coleta dados, e, sim, cria dados engendrando, a partir de informações e da relação entre elas, novas e outras informações (ALVAREZ; PASSOS, 2015). 
Pesquisas sobre o espaço urbano contemporâneo tendo como motor o Método Cartográfico procuram abarcar as distintas e múltiplas camadas que compõem o cotidiano da cidade. Essa prática torna-se inapreensível a um método que define previamente uma sequência de procedimentos que pretendem atingir um objetivo específico; em outras palavras, estruturas que operam a lógica linear de causa e efeito são refratárias ao método, pois ele coleciona informações e não infere certezas, mas disposições. Desse modo, a reversão metodológica permite a identificação de características do espaço urbano que se desviam de um objetivo inicial na pesquisa, mas que complementam e complexificam seu entendimento, seja sobre os modos de apropriação dos espaços pelos habitantes, presenças, seja sobre ausências: a manifestação material de um conjunto plural de processos que contribui para a presença dessas formas.

Deleuze e Guattari falam em seus escritos acerca da constituição de territórios existenciais. No Método Cartográfico, essa descrição da existência humana ganha corpo se investigada a partir da ação de habitar um território existencial (ALVAREZ; PASSOS, 2015). Nesse sentido, o pesquisador inserido nesse território é afetado por linhas de força, presenças ou ausências, ele as percebe, direta, ou intuitivamente e promove registros. Esse habitar é realizado dentro de uma postura receptiva, considerando as variedades da atenção do pesquisador que cartografa movimentos e processos (KASTRUP, 2015). Essa lógica permite apreender dinâmicas que procuram fugir a um repertório previamente consolidado sobre o lugar investigado.

A investigação do lugar, dentro de uma proposta de projeto de paisagem, potencialmente promove uma leitura diversificada do território para o qual se projeta, que não se limita à constatação de necessidades funcionais a serem incluídas em um programa (da rua, da praça, do parque, as tipologias consolidadas pela historiografia, ou as que se desvelam no decorrer do processo de cartografação: o que não se encaixou e restou à margem...). Frequentar o território assumindo uma postura permeável sugere apreender a diversidade de significados existentes (ou em potência) no lugar: relações que podem ser percebidas entre corpo e espaço, objetivamente ou subjetivamente, (de passagem, estar, contemplação, lazer, medo, nostalgia), entre corpo e lugar, quando singulares qualidades se apresentam.

Fundamentalmente, questões estão presentes e se desdobram em outras informações; como representar o processo que está em curso e como essas relações podem ser agenciadas: a experiência traduzida em diretrizes de projeto.

Evidencia-se o caminhar como prática essencial ao habitar do território existencial, visto que permite a aproximação do indivíduo com espaços em seus diferentes perfis, dos claramente dispostos, aos que parecem não fazer parte das lógicas e dinâmicas

10 Segundo Joan Nogué, as disciplinas que lidam com o território não abarcam o invisível, o intangível e o efêmero, aquilo que se nominou as paisagens de margem. $O$ autor propõe a incorporação desses elementos nas categorias de análise do espaço urbano e na intervenção na paisagem: o caminhar seria uma das principais ações que poderia acessar essas categorias. dominantes que promovem o funcionamento da cidade ${ }^{10}$

A título de exemplificação, poderíamos indicar uma aparente aproximação entre as propostas do Método Cartográfico e o fazer projetual de Bernard Lassus (1994). Lassus traz a ideia de intervenção mínima em seus projetos paisagísticos, nos quais ações sutis reforçam determinadas características do lugar ou transformam o modo como podem ser percebidas. $O$ arquiteto francês defende a ação do paisagista para além do domínio da visualidade, distinguindo a escala visual, na qual os fenômenos provocam sensações estritamente visuais, e a escala tátil, referente ao encontro imediato com as coisas. 
12 Tradução das autoras. No original: "II n'aurait pas été judicieux $d^{\prime}$ 'isoler la fraction dite sauvage de cette surface plutôt étendue (de l'ordre de 350 hectares) de ces bruits et de ces odeurs. J'avais plutôt la tentation d'en exalter la présence contradictoire. Face à la centrale, un fort talus surmonté d'une tour crénelée, partiellement effondrée, auurait apporté une résponse critique stigmatisant les bruits et, ainsi qu'à Jéricho, la centrale, par son bruit, aurait détruit la tour. Plus loin, dans le bois, au centre de la zone la plus sauvage de la base, un panneau aurait annoncé: "Par vent d'ouest, mousse au chocolat" (LASSUS, 1994, p. 91).
Essa escala tátil poderia ser relacionada à ideia de corpo permeável explorada por Besse ao construir a argumentação acerca da paisagem fenomenológica no ensaio "As cinco portas da paisagem" (2014). Nesse sentido, a paisagem seria o encontro entre indivíduo e mundo, caracterizado pelo atravessamento do corpo por fenômenos exteriores e pela consequente incongruência da distinção entre sujeito e objeto.

A ideia de paisagem fenomenológica pode ser identificada em um exemplo de projeto da paisagem descrito por Bernard Lassus (1994) em seu ensaio "L'obligation de l'invention". Trata-se da proposta de intervenção em uma área de lazer na cidade de Marne-la-Vallée. Lassus destaca a presença constante do ruído de automóveis e aviões no entorno e a proximidade com a usina Menier que espalhava pelo bosque uma brisa com o cheiro de chocolate. Diante dessas características, o autor narra sua experiência e propõe:

Não teria sido correto isolar a chamada fração selvagem desta área relativamente extensa (da ordem de 350 hectares) desses ruídos e cheiros. Eu estava tentado em exaltar a presença contraditória. Em frente à usina, um talude encimado por uma torre ameada, parcialmente em ruínas, trouxe uma resposta crítica estigmatizando os ruídos e, como em Jericó, a usina, por seu ruído, teria destruído a torre. Mais além, na floresta, no centro da área mais selvagem, um painel teria anunciado: "Com vento oeste, mousse de chocolate"12.

Lassus trabalha com projetos paisagísticos cujos partidos estão fortemente vinculados às características específicas do lugar, mas não apenas as da natureza física presentes, ele convoca e opera toda uma gama de questões, as quais são rearticuladas, de modo a promover através da ação de projeto e construção do lugar, novas percepções da paisagem.

A descrição e consequente configuração do lugar se faz por meio do processo de frequentação; trata-se do habitar o território existencial, nos termos do Método Cartográfico. Com o objetivo de elaboração de um projeto paisagístico, essa ação pode ser realizada por meio de "ferramentas" que auxiliam no cartografar do espaço: fotografia, registros narrativos, caderno de croquis. São ferramentas que permitem a criação de cartografias que não se limitam ao sentido convencional de mapeamento e quantificação de dados do lugar, mas que registram as características apreendidas e proporcionam a oportunidade de, ao tornar presente processos e informações de diferentes naturezas, refletir acerca de propostas de projeto baseados na articulação entre esses registros.

Acerca da ideia de registro, cumpre salientar seu papel estratégico: Georges DidiHuberman em seu trabalho intitulado Cascas (2017), descreve sua frequentação ao museu de Auschwitz-Birkenau, na Polônia, partindo de fotografias, as quais desencadeiam a formulação de reflexões desenvolvidas a partir do entrelaçamento entre sensações causadas pelo ambiente percorrido e as referências ao contexto sociocultural, histórico e político do lugar. A fotografia não é usada como documentação e ilustração; ela é registro expressivo e funciona como elemento disparador das questões abordadas e faz parte da experiência de percorrer o lugar e ter acesso às diversas camadas evidenciadas pela identificação das representações que o compõem. 
Esse trabalho de Didi-Huberman narra uma maneira de conhecer um lugar que se mantém atenta a pequenos detalhes que podem promover (disparar) o reconhecimento de uma multiplicidade de características que revelam sua espessura. E isso se torna uma estratégia de grande relevância para o projeto da paisagem, na medida em que ultrapassa a relação de diagnóstico de um problema e proposição de soluções e adentra questões que agregam particularidades a uma experiência, ampliando potencialmente a qualidade da experiência proposta.

Esse modo de propor o desenvolvimento do projeto de paisagem, em especial a leitura do território, está vinculado à reversão metodológica que caracteriza o Método Cartográfico. A frequentação do lugar e a elaboração de ações projetuais são concomitantes; na medida em que são descobertas paisagens, intenções vão sendo formuladas.

\section{Considerações finais}

Os temas da Cartografia e da Paisagem se entrelaçaram ao longo da história, indicando questões relevantes para se pensar o projeto da Paisagem no contexto contemporâneo. A imbricação entre Arte e Ciência identificada nesse percurso permite uma abordagem projetual que procura acessar as frestas entre uma concepção pragmática da realidade e sua dimensão metafísica.

O que se procurou explicitar nesse artigo foi a necessária ampliação de perspectiva à predominante abordagem ecológica do projeto de espaços livres. Fundamentada em registros históricos, a paisagem tem dimensão cultural que não pode ser posta ao largo, ao contrário, essa qualidade expressa na complexa realidade urbana contemporânea promove pistas de modos alternativos de leitura e intervenção no território.

Através do estudo historiográfico da cartografia, mostrou-se essencial constatar a articulação entre arte e ciência que moldou, através da cartografia de diversos períodos, a elaboração de modos de ver o mundo, segundo tecnologias e mentalidades específicas de cada época. Nesse sentido, a prática desenvolvida por distintos campos do conhecimento permite a identificação de um deslizamento do tema para além da abordagem estritamente científica.

Seria possível identificar a cartografia nesse contemporâneo registro como estratégia relevante para o processo de projeto da paisagem, considerando que nela concorrem um conjunto multifacetado de conceitos. Essa ação procura ultrapassar os processos de generalização em ações que sobrevoam o território e desconsideram suas especificidades. Tal dificuldade seria legado de uma tradição que busca o controle dos processos urbanos e naturais por meio da técnica e fragmenta o espaço de acordo com sua análise pautada pela descrição de funções.

Projetar a paisagem a partir do Método Cartográfico significa o enfrentamento de uma operação que apresenta diversas camadas de informação, procurando desenvolver uma estratégia que investigue as possibilidades de intervenção que sejam fruto da experiência do corpo no espaço, ações pautadas por percepções resultantes da inserção no lugar onde se realizam e materializam as práticas (ou a ausência delas) dos habitantes da cidade. 
A contribuição que tentamos promover articula dimensão estética e cultural da paisagem aportando características sutis e qualidades da experiência que muitas vezes passam despercebidas e são ignoradas pelos métodos convencionais de projeto, mas que encontram no Método Cartográfico uma possível abordagem. A cartografia na perspectiva de Deleuze e Guattari apresenta o registro de um movimento, como processo, sendo estratégia potencialmente capaz de abarcar as múltiplas camadas que constroem o cotidiano da cidade.

\section{Referências bibliográficas}

ALIATA, F; SILVESTRI, G. A paisagem como cifra de harmonia: relações entre cultura e natureza através do olhar paisagístico. Curitiba: Editora UFPR, 2008.

ALVAREZ, Johnny; PASSOS, Eduardo. Cartografar é habitar um território existencial. In: PASSOS, Eduardo; KASTRUP, Virgínia; ESCÓSSIA, Liliana da. (Org.). Pistas do método da cartografia: pesquisa-intervenção e produção de subjetividade. Porto Alegre: Sulina, 2015.

BARTALINI, Vladimir (Org.). Paisagem Textos 1. São Paulo: FAUUSP, 2013.

BERQUE, Augustin. Paysage, milieu, histoire. In: BERQUE, A. (Org.) Cinq propositions pour une théorie du paysage. Mayenne: Champ Vallon, 1994.

BESSE, Jean-Marc. O gosto do mundo: exercícios de paisagem. Rio de Janeiro: Eduerj, 2014

BESSE, Jean-Marc. Ver a terra: seis ensaios sobre a paisagem e a geografia. São Paulo: Perspectiva, 2006.

CERTEAU. Michel de (1980). A invenção do cotidiano: artes de fazer. Petrópolis: Editora Vozes, 2007.

COSGROVE, Denis. Introduction: mapping meaning. In COSGROVE, Denis (Org.). Mappings. London: Reaktion Books, 1999.

DARDEL, Eric (1952). O homem e a terra: natureza da realidade geográfica. São Paulo: Perspectiva, 2011.

DELEUZE, Gilles; GUATTARI, Félix (1980). Mil Platôs - vol. 1. São Paulo: Editora 34, 1995.

DIDI-HUBERMAN, Georges. Cascas. São Paulo: Editora 34, 2017.

HERZOG, Cecília Polacow; ROSA, Lourdes Zunino. Infraestrutura Verde: Sustentabilidade e resiliência para a paisagem urbana. Revista LABVERDE, São Paulo, n. 1, p. 92-115, set. 2010. ISSN 2179-2275. Disponível em: <https://www.revistas.usp.br/revistalabverde/ article/view/61281/64217>. Acesso em: 14 ago. 2017. doi: <http://dx.doi.org/10.11606/ issn.2179-2275.v0i1p92-115>.

HOUGH, Michael. Naturaleza y ciudad. Barcelona: GG, 1998.

JACQUES, P. B.; BRITTO, F.D.; DRUMMOND, W. (Org.). Experiências Metodológicas para compreensão da complexidade da cidade contemporânea. Salvador: EDUFBA, 2015.

JACQUES, Paola B. Errâncias urbanas: a arte de andar pela cidade. Arqtexto, Porto Alegre, n. 7, p. $16-25,2005$.

KASTRUP, Virgínia. O funcionamento da atenção no trabalho do cartógrafo. In: PASSOS, Eduardo; KASTRUP, Virgínia; ESCÓSSIA, Liliana da. (Org.). Pistas do método da cartografia: pesquisa-intervenção e produção de subjetividade. Porto Alegre: Sulina, 2015.

LASSUS, Bernard. L'obligation de l'invention: du paysage aux ambiances successives. In: BERQUE, A. (Org.) Cinq propositions pour une théorie du paysage. Mayenne: Champ Vallon, 1994. 
MADERUELO, Javier. Maneras de ver el mundo: de la cartografía al paisaje. In: MADERUELO, Javier (Org.). Paisaje y territorio. Madrid: Abada, 2008.

MCHARG, Ian (1969). Design with Nature. Jonh Wiley \& Sons Inc., 1992.

MERLEAU-PONTY, Maurice (1945). Fenomenologia da percepção. São Paulo: Martins Fontes, 1994.

MERLEAU-PONTY, Maurice (1961). O olho e o espírito. São Paulo: Cosac Naify, 2013.

NOGUÉ, Joan. Al margen: los paisajes que no vemos. In: MADERUELO, Javier (Org.). Paisaje y territorio. Madrid: Abada, 2008.

PASSOS, Eduardo; KASTRUP, Virgínia; ESCÓSSIA, Liliana da. (Org.). Pistas do método da cartografia: pesquisa-intervenção e produção de subjetividade. Porto Alegre: Sulina, 2015

ROGER, Alain. Breve tratado del paisaje. Madrid: Biblioteca Nueva, 2007

SCAFI, Alessandro. Mapping Eden: cartographies of the earthly paradise. In: COSGROVE, Denis (Org.). Mappings. London: Reaktion Books, 1999.

SCHENK, Luciana. B. M. Arquitetura da paisagem: entre o Pinturesco, Olmsted e o Moderno. Tese de Doutorado. São Carlos: EESC/USP, 2008.

SPIRN, Anne (1984). W. O jardim de Granito. São Paulo: Edusp, 1995. 